\title{
Design and Construction of a prototype of Ergonomic Pad controlled through Electronic Sensors to Correct Bad Postures on Office Workers and Its Impact on Productivity
}

\author{
Juan M Dulce Fernández ${ }^{\mathrm{a}^{*}}$,Laura M Pimienta Carbonell ${ }^{\mathrm{a}^{* *}}$ \\ ${ }^{a}$ Engineering and production Sciences Department, Faculty of Engineering, Pontificia Universidad Javeriana, \\ Cali, Colombia
}

\begin{abstract}
The design of the electronic pad for office chairs, required to identify the needs and difficulties of an office user, by initially conducting surveys and observational studies that allowed to identify ergonomic deficiencies in the workplace, and user's bad habits, which were reflected in back pain, neck and shoulder affections and some diseases caused by these symptoms, that finally impacted on worker's health and productivity.
\end{abstract}

Keywords: Job Analysis and work design; human factors engineering; occupational health, ergonomics in design, Musculoskeletal Disorders

\section{Introduction}

Many jobs require workers to sit for long periods of time (work shifts of more than 4 hours per day). This sedentary behavior at workplaces poses musculoskeletal risks for the workers. In Colombia, for example, studies have concluded that low back pain is very common in office workers and is the third cause of absenteeism from work. [1]

This study accordingly applied concepts of ergonomics to design a product that prevents and decreases musculoskeletal risks, based on the analysis of factors influencing the worker's physical wellbeing. Job requirements and workplace design were also taken into account.

\section{Background information}

Nowadays, working at the computer is almost inevitable to perform most office jobs. Both small and large companies use modern technology, in particular computers. As a result, a large part of the working population spends 8 hours or more each day in a sedentary position. This means that the physical wellbeing of office staff depends largely on how well designed are the chairs, work stations, and other furnishings that make up the work environment.

In a study carried out by the Herman Miller Group, 40 office employees were observed over 160 hours and concluded that these employees worked sitting down $93 \%$ of the time. This evidences that office work is characterized by the lack of physical movement, which leads to improper posture, which, in turn, can cause abdominal problems; pains in the back, neck, and shoulders; lesions to spine; circula-

\footnotetext{
*Juan Manuel Dulce Fernández. E-mail: jmdulce@javeriancali.edu.co

*** Laura Pimienta Carbonell. E-mail: 1mpimienta@javeriancali.edu.co
} 
tion problems, musculoskeletal complications such as spondylitis, cervicalgia, and lumbalgia. [2]

Studies carried out by the University of Queensland in Australia have also confirmed the relationship between sedentary lifestyle and cardiac diseases.

"Total sedentary time is deleteriously associated with different biomarkers, while interruptions or breaks, regardless of the sedentary time, are beneficially associated with waist circumference, Creactive protein, and plasma glucose. These findings have specific implications for jobs that involve long periods of sitting down, such as at office work stations" [3]

In its 2010 national pain survey, the Colombian Association for the Study of Pain (ACED, its Spanish acronym) classified different activities according to the effort that active employees and independent workers must make to perform their jobs and found that jobs involving greater levels of intellectual work (office-related jobs) are more related to musculoskeletal diseases and pains, as shown in Figure 1. [1]

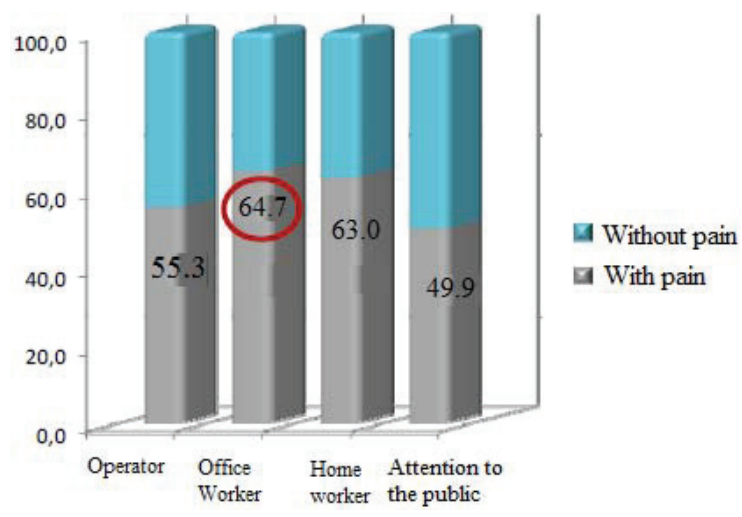

Figure 1.Occupation and classification of effort needed to perform different jobs.

Source: ACED.

In the case of Colombian workers, this type of pain affects the daily habits of $79.5 \%$, the sleeping habits of $58.5 \%$, and the everyday activities of $36.7 \%$ (Figure 2). Pain-related diseases reduce work productivity or lead to absenteeism from work. During 2010, $85.4 \%$ of the population took from 0 to 3 days sick leave (Figure 3 ), costing employers and health care providers almost COP 23 billion based on the 2010 minimum legal salary in force and the average number of sick days within the range.[1]

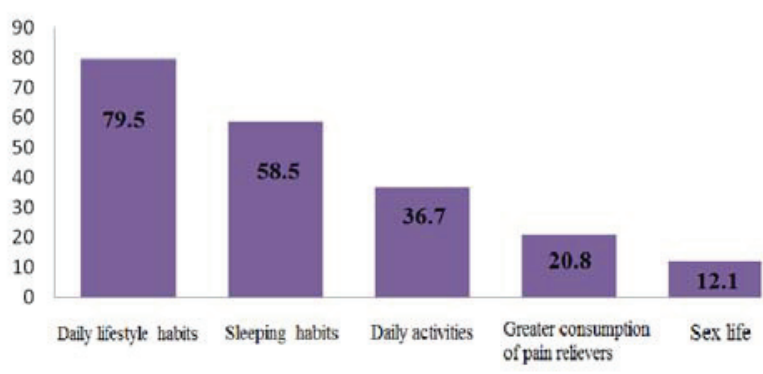

Figure 2. Activities affected by pain-related diseases. Source: ACED.

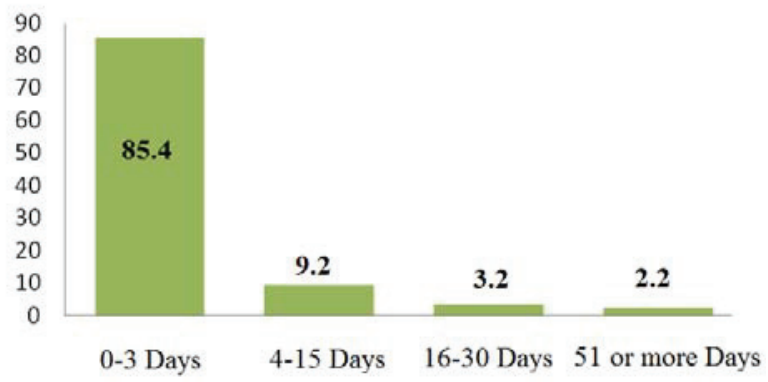

Figure 3. Days of sick leave due to pain-related diseases. Source: ACED.

\section{Research and Design}

Once the problem was identified, the study initially focused on the office work station to better understand the problem of bad posture.

The initial research stage involved exploratory testing and observation. User-oriented design methodologies currently used by Stanford University, such as IDEO cards ${ }^{1}$, were used, complemented by brainstorming sessions and focus groups, which served to clearly identify ergonomic problems at the work station, analyzing factors of design, comfort, and wellbeing.

The observations covered a timeframe of 160 hours, from 8 a.m. to 6 p.m., during which the work stations, seating, and postures of employees of five different companies of Cali, Colombia, were analyzed.

The IDEO cards served to make long range forecasts, which addressed the following issues:

\footnotetext{
${ }^{1}$ Design research methodology developed by IDEO that consists in using specialized letters that contained user-oriented tests and activities.
} 
- How. Scenarios are built that describe how technological and/or social trends can influence not only people's behavior but also the use of a product, service, or mean.

- Why. Predicting changes in industrial or technological performance can help clients understand the implications of design decisions. Research can help determine future trends of modern technological design that will have a direct impact on the posture of people who remain seated during most of their work day.

A group of 15 individuals, ages 18 and above, were randomly selected at the Javeriana UniversityCali campus. A brainstorming session was held, focusing on factors that could directly or indirectly affect work station design. Ideas and proposals were extensively discussed. Brainstorming was found to help strengthen creativity and trigger new technological ideas.

Based on the exploratory testing, it was concluded that most of the work stations of the offices included in the observations made during the exploratory process do comply with standard and even strict ergonomic standards. But even so, users present poor posture and suffer from back, shoulder, and neck pains as if these ergonomic conditions were not enough. The question then arises whether posture problems are only caused by improper design of work stations, chairs and other office elements or if they can also be attributed to poor posture habits of the users.

The second phase consisted in developing a proposal that goes beyond the traditional design of work stations, seeking to understand and analyze the interaction of the user with the chair and his/her posture throughout the work day, while complying with modern technology trends.

Several prototypes were accordingly developed and submitted to multiple tests with end users. Experts in the fields of Occupational Health, Ergonomics, Physical Therapy, Industrial Design, and Industrial and Electronic Engineering also provided valuable input and feedback, allowing the research team to consolidate a user-oriented tool complying with the highest quality standards.

The resulting product was an electronically controlled cushion, adaptable to the seat and back of a standard chair. The cushion has sensors that identify the user's posture and, after a determined amount of time, if his/her posture has been poor, it will send a vibration signal to the base of the cushion, notifying the user of his/her poor posture (Figure 4).

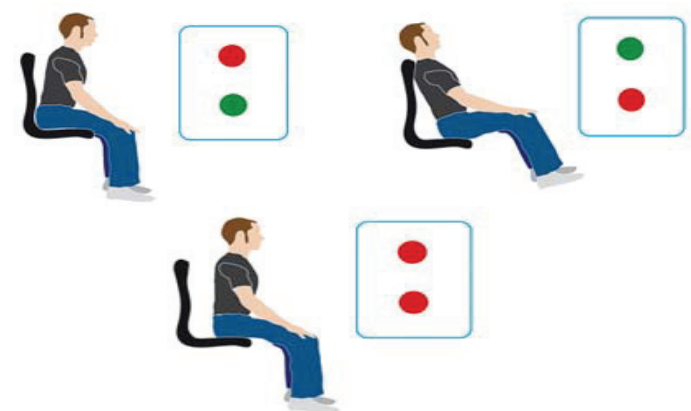

Figure 4. Electronically controlled cushion with sensors that detect poor posture.

\section{Field Tests and Results}

With the main purpose of test the functionality of the ergonomic pad, a field test was performed for 8 Secretaries at Javeriana University (Cali, Colombia), the procedure and objectives for the tests are described below:

\section{Procedure:}

- Apply a diagnostic survey to evaluate ergonomic elements of workplace and health for each of the secretaries.

- Install the ergonomic pad at the chair of each secretary to collect information about posture habits, each test has an average duration of 6 hours.

- The collected data will be extracted from the database to a worksheet in order to be analyzed and consolidated.

Objectives:

- Implement the prototype pad in order to evaluate its functionality and applicability at offices and workplaces.

- Analyze posture habits individually and in a consolidated way, in order to identify the causes for bad postures and existing health risk factors for the evaluated secretaries.

\subsection{Diagnostic Survey}

A diagnostic survey was applied for each secretary, the elements evaluated was mainly the perception of each secretary about her own posture, work 
performance, health conditions and sedentarism at workplace.

First question was intended to evaluate the perception of comfort for the workplace of each secretary (Figure 5).

Further evaluation of each chair, led to the conclusion that even when some secretaries used the exact same chair, some felt comfortable with it while others didn't. This subjective difference may also find an answer on posture habits of each secretary (Figure $6)$.

From 8 evaluated secretaries, 3 that consider having a bad posture also feel uncomfortable with their chairs, whereas, 3 secretaries that think have a good posture feel comfortable with their chairs.

\section{You consider that the chair assigned for your workplace is:}

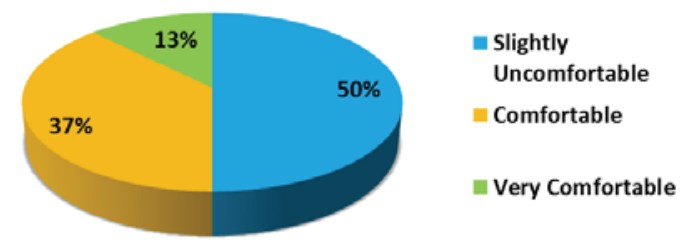

Figure 5. Work Chair Perception.

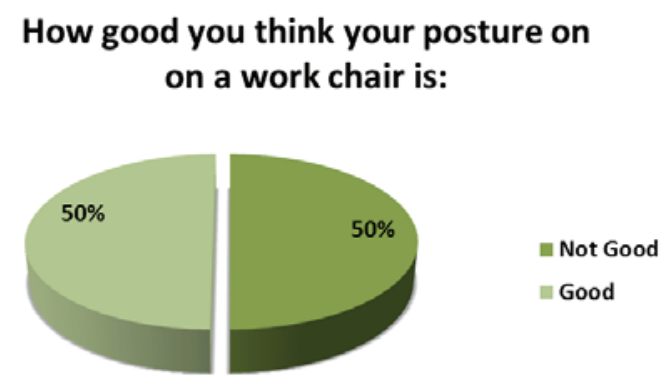

Figure 6. Sitting Posture Perception.

Results show that all of the evaluated secretaries suffer pain in upper body zones, and particulary $62.5 \%$ of them experiment back pain (Figure 7).
At the end of the day, in which of the following zones do you experiment more pain

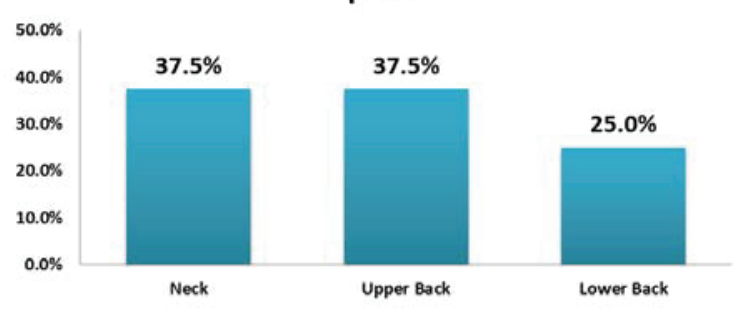

Figure 7. Pain Conditions.

Finally, the secretaries answered about their sendentarism habits, even all of them turn into standing position frequently (Figure 8 ), just $37 \%$ of them perform active breaks (Figure 9), which require stretching exercies.

\section{How often do you stand up from your work chair}

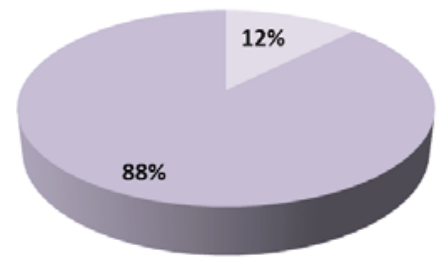

Not Often

Frequently

Figure 8. Stand up Frequency.

\section{Do you perform active breaks}

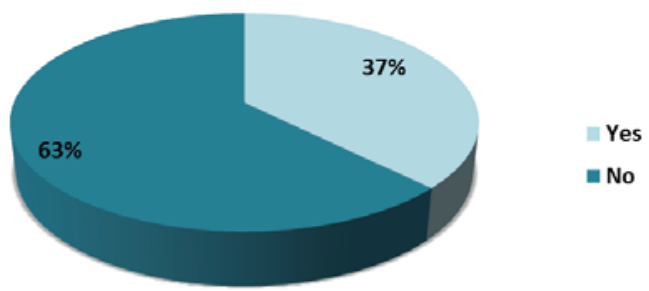

Figure 9. Active Breaks.

\subsection{Field Results}

In order to facilitate data analysis, 5 types of postures were defined (Figure 10), being Posture 1 when worker is absent of his/her chair. 


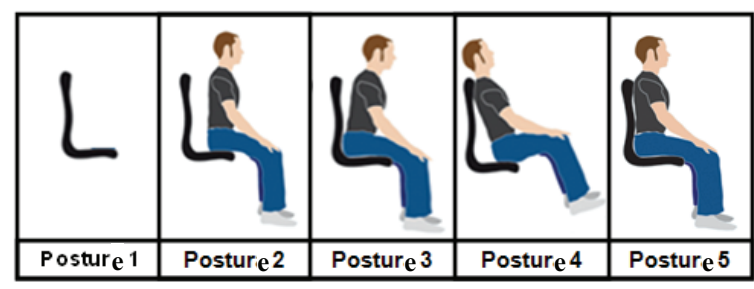

Figure 10. Postures evaluated

This research led to the first conclusion that posture habits for each secretary don't follow a pattern over time, there are several factors that affect sitting posture, such as, sitting habits, tasks performed by user and workstation design. Therefore wouldn't be correct to apply probabilistic models to predict or forecast the posture of a worker over time.

Using the data gathered, it was identified that most common sitting posture for the 8 secretaries is Posture 3 , which consists on inclined posture while upper back is not supported on chair. On average $32 \%$ of time secretaries presented that posture (Table 1), and just $22 \%$ of time they had a good posture.

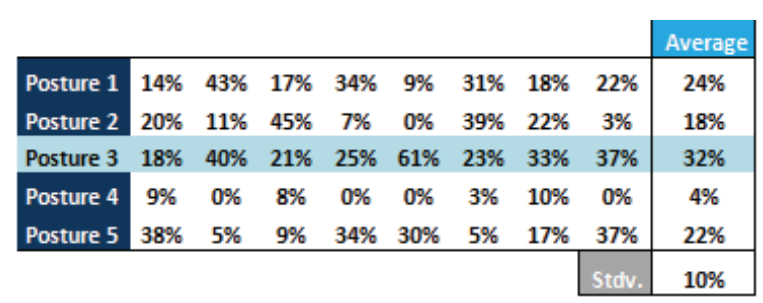

Table 1. Time distribution (\%) of postures for each of the secretaries.

Additionally, frequencies of postures for all secretaries were calculated (Table 2), the results showed that each 2,4 minutes a secretary changes her posture (from those defined on Figure 6). Also results showed that on average a secretary is sitting on her chair for 27,4 minutes before standing up. Other fact gathered from research is that on average after a secretary stands up her chair, she spends 6,5 minutes on standing position.

\begin{tabular}{|c|c|c|c|c|c|c|c|c|c|}
\hline & & & & & & & & & Average \\
\hline $\begin{array}{l}\text { POSTURE } \\
\text { DURATION } \\
\text { (min) }\end{array}$ & 1,8 & 3,8 & 2,8 & 1,9 & 2,7 & 1,9 & 2,2 & 2,4 & 2,4 \\
\hline $\begin{array}{l}\text { SITTING } \\
\text { DURATION } \\
\text { (min) }\end{array}$ & 14,0 & 15,3 & 31,7 & 43,8 & 45,1 & 10,3 & 53,6 & 5,8 & 27,4 \\
\hline $\begin{array}{l}\text { STANDING } \\
\text { DURATION } \\
\text { (min) }\end{array}$ & 2,2 & 9,8 & 4,3 & 10,9 & 12,3 & 4,3 & 4,2 & 3,6 & 6,5 \\
\hline
\end{tabular}

Table 2. Calculated frequencies: Posture switch frequency, sitting duration and standing duration.

\subsection{Research Conclusions}

There are several factors that influence sitting postures, such as sitting habits, worker activities and workplace design, in this research we identified that sitting postures don't follow a defined pattern over time and can't be adapted to probabilistic distributions.

This research also showed that secretaries don't suffer high sedentary risks, as they stand up each 30 minutes, but they must be trained to correct their postures by using the ergonomic pad, since their more frequent posture is Posture 3 which they adopt $32 \%$ of time, along with other bad postures it sums 54\%, in contrast they just present a correct posture for $22 \%$ of time.

For detailed information and analysis for this research please contact the authors.

\section{References}

[1] Asociación Colombiana del Dolor Lumbar ACED. Quinto estudio del dolor nacional del 2010. On line]. [Accessed on 2 December 2010]. Available at http://www.dolor.org.co/

[2] The Herman Miller Group. Body Support in the office. Sitting, Seating and Low back Pain. 2002. p.1.

[3] G. N. Healy, C. E. Matthews, D. W. Dunstan, E. A. H. Winkler, N. Owen. Sedentary time and cardio-metabolic biomarkers in US adults: NHANES 2003-06. European Heart Journal, 2011; p. 4 